\title{
Efficacy and harm of pharmacological prevention of acute mountain sickness: quantitative systematic review
}

\author{
Lionel Dumont, Chahé Mardirosoff, Martin R Tramèr
}

\begin{abstract}
Objective To quantify efficacy and harm of pharmacological prevention of acute mountain sickness.

Data sources Systematic search (Medline, Embase, Cochrane Library, internet, bibliographies, authors) in any language, up to October 1999.

Study selection Randomised placebo controlled trials.

Data extraction Dichotomous data on efficacy and harm from 33 trials (523 subjects received 13 different interventions, 519 a placebo).

Data synthesis At above $4000 \mathrm{~m}$ the mean incidence of acute mountain sickness with placebo was $67 \%$ (range 25\% to $100 \%$ ); incidence depended on the rate of ascent, but not on the altitude or the mode of ascent. Across all ascent rates, dexamethasone 8-16 mg prevented acute mountain sickness (relative risk 2.50 (95\% confidence interval 1.71 to 3.66$)$; number needed to treat (NNT) 2.8 (2.0 to 4.6$)$ ), without evidence of dose responsiveness. Acetazolamide $750 \mathrm{mg}$ was also efficacious (2.18 (1.52 to 3.15); NNT 2.9 (2.0 to 5.2)), but $500 \mathrm{mg}$ was not. In two trials, adverse reaction (including depression) occurred after dexamethasone was stopped abruptly (4.45 (1.08 to 18 ); NNT 3.7 (2.5 to 6.9$)$ ). With acetazolamide, paraesthesia (4.02 (1.71 to 9.43); NNT 3.0 (2.0 to 6.0$)$ ) and polyuria (4.24 (1.92 to 9.37$)$; NNT 3.6 (2.5 to 6.2$)$ ) were reported. Data were sparse on nifedipine, frusemide (furosemide), dihydroxyaluminium-sodium, spironolactone, phenytoin, codeine, phenformin, antidiuretic hormone, and ginkgo biloba.

Conclusions At above $4000 \mathrm{~m}$, with a high ascent rate, fewer than three subjects need to be treated with prophylactic dexamethasone $8-16 \mathrm{mg}$ or acetazolamide $750 \mathrm{mg}$ for one subject not to experience acute mountain sickness who would have done so had they all received a placebo.

Acetazolamide $500 \mathrm{mg}$ does not work.
\end{abstract}

\section{Introduction}

Every year thousands of people who live at low altitudes climb or work in high altitude areas. Many of them experience acute mountain sickness. The most common symptoms (headache, loss of appetite, nausea, fatigue, dizziness, and insomnia) usually appear within the first three days of arrival at high altitude. ${ }^{1-3}$

Acute mountain sickness is not only uncomfortable; it is also partly responsible for an increased mortality at high altitude. Many drugs have been used to try to prevent or alleviate symptoms of the sickness. The US Food and Drug Administration has proposed acetazolamide in susceptible subjects, or when the rules of acclimatisation cannot be respected. ${ }^{4}$ The most widely recommended dose is $500 \mathrm{mg}^{5{ }^{6}}$ Others have questioned the efficacy of acetazolamide. ${ }^{78}$
Dexamethasone has been recommended when there are contraindications for acetazolamide. ${ }^{5}$

We aimed to quantify the efficacy and harm of drugs that are currently used to prevent acute mountain sickness.

\section{Methods}

Inclusion criteria

We included full reports of randomised comparisons of any pharmacological intervention that is thought to decrease the risk of acute mountain sickness with a placebo (that is, intervention versus a control). Trials had to report relevant end points in dichotomous form.

\section{Systematic search}

We searched systematically in Medline (last search 15 October 1999), Embase (9 November 1998), the Cochrane Library (issue 1, 1999), and the high altitude bibliography website (http://libwww.aoc.nrao.edu/ aoclib/highalt.html, 15 October 1999) using the following search terms as MeSH headings and text words: "acute mountain sickness," "altitude," "prevention," "prophylaxis," "acetazolamide," "dexamethasone," and "random." We checked bibliographies of retrieved reports and review articles. ${ }^{9}$ We did not consider data from abstracts or letters.

\section{Extraction of data}

The primary end point of interest was complete prevention of acute mountain sickness according to the original authors' definition. Other end points of interest were prevention of headache, nausea, insomnia, and dizziness. If several measurements had been conducted at different time points, we extracted the worst result for both intervention and control. Data on adverse drug reactions were extracted when they were reported in dichotomous form.

\section{Critical appraisal}

Retrieved reports were checked for inclusion by one author (LD). Potentially relevant reports were then read by all authors independently and assessed using the validated three item, five point Oxford score. ${ }^{10}$ The authors met to agree a consensus.

\section{Quantitative analysis}

Relative risks were calculated with 95\% confidence intervals. ${ }^{11}$ A fixed effect model was used to combine data (all data were homogenous). ${ }^{12}$ As an estimate of the absolute effort required for one subject to profit from prophylaxis compared with placebo (for harm, for one subject to show an adverse effect), we calculated the number needed to treat (NNT) with 95\% confidence interval. ${ }^{13}{ }^{14}$

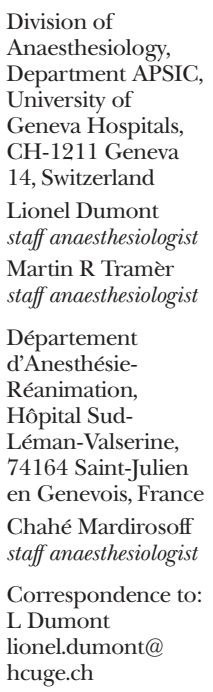

Département

d'Anesthésie-

Réanimation,

Hôpital Sud-

Léman-Valserine,

74164 Saint-Julien

en Genevois, France

Chahé Mardirosoff

staff anaesthesiologist

Correspondence to:

L Dumont

lionel.dumont@

hcuge.ch

BMJ 2000;321:267-72 


\section{Results}

\section{Excluded and included trials}

We retrieved 52 randomised trials; 19 were subsequently excluded. Seventeen had no dichotomous data of relevant end points (data from one of those ${ }^{15}$ were published in two subsequent full reports ${ }^{16}{ }^{17}$ ). Of those that did report dichotomous data, two ${ }^{18}$ were published twice ${ }^{2021}$; original data only were analysed. ${ }^{18} 19$ We contacted 30 authors by letter; five responded. No additional relevant data were retrieved.

We analysed 33 trials, published in 31 full reports from 1965 to $1998 .{ }^{1}{ }^{18} 1922-49$ Data extracted from these trials are available at www.hcuge.ch/anesthesie/anglais/ research/ammtrials.htm.

The mean trial size was 15 (range 4-38) subjects per group; 523 subjects received one of 13 interventions, 519 a placebo. The mean final altitude was 4432 (20505895 ) metres, and the mean exposure time was 90 (12$240)$ hours. The median quality score was 3 (2-5). We considered that 17 of 33 trials used an adequate method of blinding-for example, tablets of identical shape, colour, and taste.

\section{Control event rate and underlying risk}

Numerous different scores, gradings, and definitions of acute mountain sickness were used in the original reports. Complete absence of acute mountain sickness was a clearly defined end point in 20 trials. ${ }^{1} 19232630-322^{35-3739-49}$ In 18 of those, final altitude was $4050 \mathrm{~m}$ to $5885 \mathrm{~m}$; the mean control event rate (that is, the mean incidence of acute mountain sickness with placebo) was $67 \%$ (range $25-100 \%$ ). The other two trials were performed at lower altitudes (2050 $\mathrm{m}$ and $2700 \mathrm{~m}) .^{41}$ In these, the control event rates were below 30\%. We assumed that these two trials represented different experimental conditions and excluded them from further analyses. In the 18 trials reporting the incidence of acute mountain sickness at above $4000 \mathrm{~m}$, no relation existed between altitude and control event rate (fig 1 (top)).

To take into account very fast rates of ascent, we calculated an index of metres/hour, although ascent rate is usually expressed as metres/day. Mean ascent rates, when not reported in original trials, were extrapolated using the altitude difference (that is, final altitude minus altitude at start) and duration of ascent. A direct relation existed between ascent rates and control event rates (fig 1 (bottom)). Four modes of ascent were identified; they represented four different ranges of ascent rates and control event rates (table 1). For all, a direct relation existed between ascent rate and control event rate (fig 1 (bottom)).

\section{Qualitative analysis of efficacy}

The incidence of acute mountain sickness with interventions and placebo was plotted for all 18 trials (22 comparisons) that related to ascents to $4050-5890 \mathrm{~m}$ and which reported acute mountain sickness (fig 2 ). For two comparisons, the intervention (codeine $132 \mathrm{mg}^{30}$ and nifedipine $20 \mathrm{mg}^{36}$ ) was less efficacious than the placebo. There was equivalence in one small trial testing acetazolamide $500 \mathrm{mg}{ }^{42}$ For 19 comparisons, the results suggested both superiority of the intervention and relative homogeneity of the data. For both dexamethasone and acetazolamide, smaller and larger trials were equally distributed among the event rate scatter, suggesting that there was no relation between trial size and efficacy of interventions.

\section{Quantitative analysis}

Dexamethasone and acetazolamide

Dexamethasone was tested in eight trials with exposure above $4000 \mathrm{~m}$ (mean $4486 \mathrm{~m}$ (range 4050-5334 m)) and acute mountain sickness as an end point. ${ }^{23} 31323539444549$ Across all ascent rates, daily doses of dexamethasone $8 \mathrm{mg}, 12 \mathrm{mg}$, and $16 \mathrm{mg}$ were more
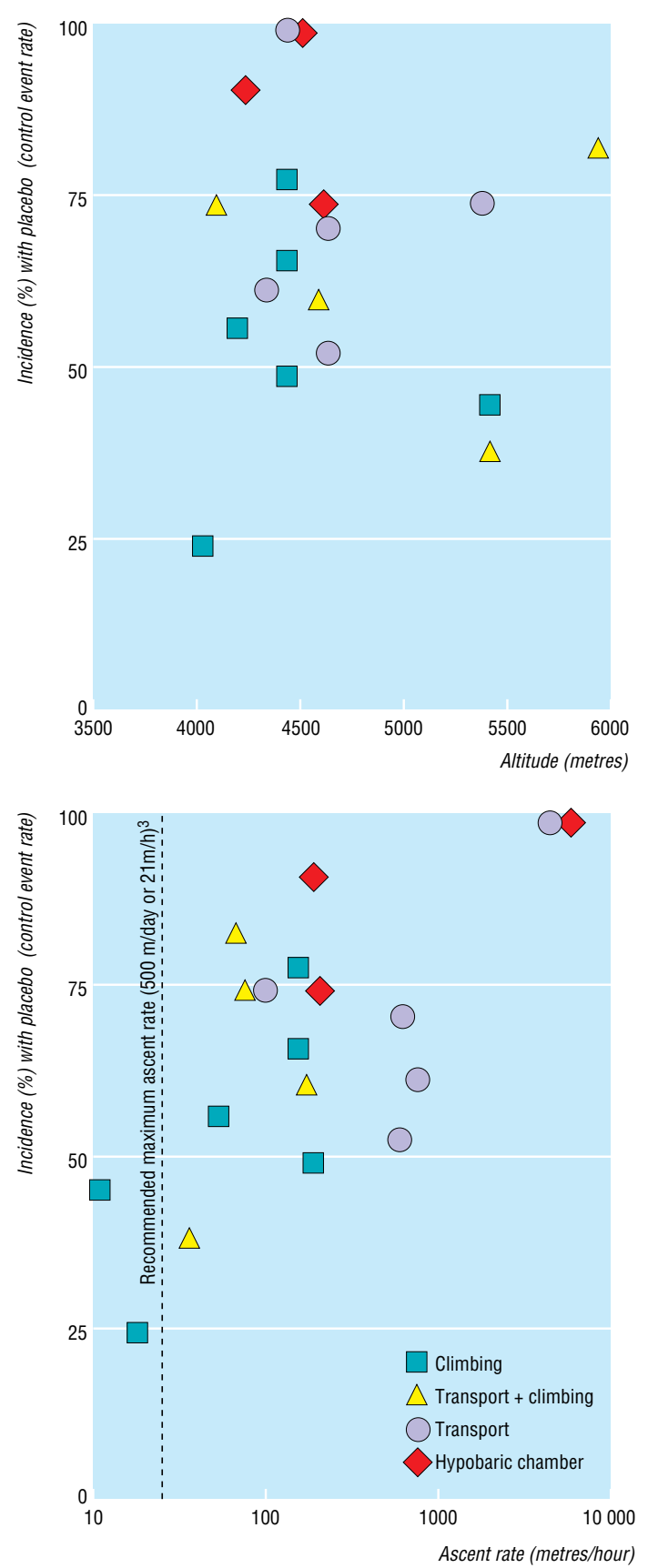

Fig 1 Incidence of acute mountain sickness in subjects receiving placebo (control event rate) in relation to final altitude (top), rate of ascent (bottom), and mode of ascent. Each symbol represents one trial; symbol sizes do not take into account trial sizes 


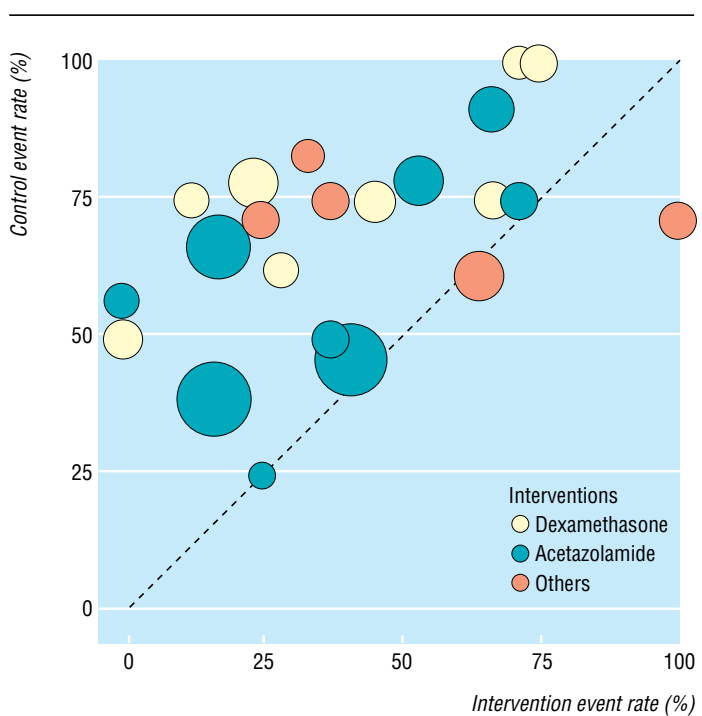

Fig 2 Incidence of acute mountain sickness with interventions and with placebo (18 trials, 22 comparisons). Symbol sizes are proportional to trial sizes. "Others"=codeine, phenformin, nifedipine, spironolactone, and dexamethasone plus acetazolamide. The dotted line represents equality

efficacious than placebo (NNT 2-3) (table 2). In one trial daily doses of $0.5 \mathrm{mg}$ and $2 \mathrm{mg}$ dexamethasone were tested; neither dose had any effect on acute mountain sickness. ${ }^{45}$

Acetazolamide was tested in nine trials with exposure above $4000 \mathrm{~m}$ (mean $4478 \mathrm{~m}$ (range 4000-5356 m)) and acute mountain sickness as an end point. ${ }^{1} 19313240424749$ Across all ascent rates, acetazolamide $750 \mathrm{mg}$ was more efficacious than placebo (NNT
Table 1 Data from 18 randomised trials on acute mountain sickness performed at 4050-5890 $\mathrm{m}$ and reporting absence of acute mountain sickness. Values are means (ranges)

\begin{tabular}{|c|c|c|c|c|}
\hline Mode of ascent & $\begin{array}{l}\text { No of } \\
\text { trials }\end{array}$ & Final altitude (m) & Rate of ascent $(\mathrm{m} / \mathrm{h})$ & $\begin{array}{l}\text { Incidence }(\%) \text { of } \\
\text { acute mountain } \\
\text { sickness with } \\
\text { placebo }\end{array}$ \\
\hline Climbing* & 6 & $4450(4000-5356)$ & $91(10-176)$ & $54(25-79)$ \\
\hline Transport plus climbing $\dagger$ & 4 & 4963 (4050-5885) & $82(34-156)$ & $65(39-83)$ \\
\hline Transportł & 5 & 4647 (4300-5334) & $1268(74-4400)$ & $73(53-100)$ \\
\hline Hypobaric chamber§ & 3 & 4407 (4200-4570) & $1647(179-4570)$ & $89(75-100)$ \\
\hline
\end{tabular}

*Subjects walk to the final altitude.

†Subjects are first transported by car or cable car and then walk to the final altitude.

$\ddagger$ Subjects are transported to the final altitude by aeroplane, car, helicopter, or cable car.

$\S$ Subjects are placed in a chamber in which the atmospheric pressure can be decreased according to a study protocol.

2-3). Acetazolamide $500 \mathrm{mg}$ was not significantly different from placebo (NNT 7) (table 2).

For both dexamethasone and acetazolamide a direct relation existed between ascent rate and relative risk (fig 3). The NNT, however, was very high or negative with low ascent rates, decreased with increasing ascent rates, and remained almost constant when ascent rates were $>500 \mathrm{~m} /$ day (fig 3).

Other end points were prevention of insomnia, headache, nausea, and dizziness (table 2). For dexamethasone, these were reported in one trial with a limited number of subjects; results were inconclusive. For acetazolamide, tested in five trials reporting these end points, all results were in favour of acetazolamide; numbers needed to treat were between three and six.

\section{Other interventions}

Nifedipine $60 \mathrm{mg}$ and spironolactone $75 \mathrm{mg}$ and $100 \mathrm{mg}$ were tested in two trials each. In one, nifedipine was more efficacious than placebo for the

Table 2 Data on efficacy and adverse reactions with acetazolamide and dexamethasone for prevention of acute mountain sickness

\begin{tabular}{|c|c|c|c|c|c|c|c|}
\hline \multirow[b]{2}{*}{ End point } & \multicolumn{2}{|c|}{ Incidence (\%) of disease } & \multicolumn{2}{|c|}{$\begin{array}{l}\text { Total No of subjects/No of } \\
\text { subjects with end point }\end{array}$} & \multirow{2}{*}{$\begin{array}{l}\text { Relative risk } \\
(95 \% \mathrm{Cl})\end{array}$} & \multirow{2}{*}{$\begin{array}{l}\text { No needed to } \\
\text { treat }(95 \% \mathrm{CI})\end{array}$} & \multirow[b]{2}{*}{ References } \\
\hline & Intervention & Control & Intervention & Control & & & \\
\hline \multicolumn{8}{|l|}{ Prevention of acute mountain sickness } \\
\hline $8 \mathrm{mg}, 12 \mathrm{mg}$, or $16 \mathrm{mg}$ & 37.7 & 73.8 & $48 / 77$ & $22 / 84$ & 2.50 (1.71 to 3.66$)$ & $2.8(2.0$ to 4.6$)$ & $23,31,32,35,39,44,45,49$ \\
\hline $8 \mathrm{mg}$ & 59.3 & 86.2 & $11 / 27$ & $4 / 29$ & 2.97 (1.10 to 8.02) & 3.7 (2.0 to 22$)$ & $23,35,45$ \\
\hline $12 \mathrm{mg}$ & 14.8 & 62.5 & $23 / 27$ & $12 / 32$ & $2.53(1.54$ to 4.16$)$ & $2.1(1.4$ to 3.8$)$ & 31,32 \\
\hline \multicolumn{8}{|l|}{ Acetazolamide: } \\
\hline $500 \mathrm{mg}$ or $750 \mathrm{mg}$ & 32.7 & 58.5 & $103 / 153$ & $59 / 142$ & $1.58(1.27$ to 1.96$)$ & $3.9(2.7$ to 6.8$)$ & $1,19,31,32,40,42,47,49$ \\
\hline $500 \mathrm{mg}$ & 31.7 & 45.9 & $56 / 82$ & $33 / 61$ & 1.22 (0.93 to 1.59) & $7.0(3.3$ to -54$)$ & $1,42,49$ \\
\hline $750 \mathrm{mg}$ & 33.8 & 67.9 & $47 / 71$ & $26 / 81$ & 2.18 (1.52 to 3.15$)$ & $2.9(2.0$ to 5.2$)$ & $19,31,32,40,47$ \\
\hline \multicolumn{8}{|l|}{ Prevention of insomnia } \\
\hline Dexamethasone $12 \mathrm{mg}$ & 64.7 & 92.9 & $6 / 17$ & $1 / 14$ & $4.94(0.67$ to 36.3$)$ & 3.6 (1.8 to 58$)$ & 31 \\
\hline Acetazolamide $750 \mathrm{mg}$ or $1 \mathrm{~g}$ & 40.0 & 77.1 & $45 / 75$ & $25 / 76$ & 1.84 (1.27 to 2.66$)$ & 3.7 (2.4 to 8.5$)$ & $31,33,37,40$ \\
\hline \multicolumn{8}{|l|}{ Prevention of headache } \\
\hline Acetazolamide $500 \mathrm{mg}, 750 \mathrm{mg}$, or $1 \mathrm{~g}$ & 25.9 & 62.2 & $60 / 81$ & $31 / 82$ & 1.96 (1.45 to 2.64) & 2.8 (2.0 to 4.5$)$ & $27,31,33,37,40$ \\
\hline \multicolumn{8}{|l|}{ Prevention of nausea } \\
\hline Dexamethasone $12 \mathrm{mg}$ & 11.8 & 42.9 & $15 / 17$ & $8 / 14$ & 1.54 (0.95 to 2.51) & 3.2 (1.6 to 102$)$ & 31 \\
\hline Acetazolamide $500 \mathrm{mg}, 750 \mathrm{mg}$, or $1 \mathrm{~g}$ & 20.1 & 36.3 & $68 / 85$ & $55 / 86$ & 1.26 (1.04 to 1.52) & 6.2 (3.4 to 35$)$ & $27,29,31,33,37,40$ \\
\hline \multicolumn{8}{|l|}{ Prevention of dizziness } \\
\hline Dexamethasone $12 \mathrm{mg}$ & 23.5 & 64.3 & $13 / 17$ & $5 / 14$ & 2.14 (1.01 to 4.54$)$ & 2.5 (1.4 to 12$)$ & 31 \\
\hline $\begin{array}{l}\text { Adverse reactions from weaning from } \\
\text { dexamethasone }\end{array}$ & 27.1 & 0 & $13 / 48$ & $0 / 43$ & 4.45 (1.08 to 18.3$)$ & $3.7(2.5$ to 6.9$)$ & $23,24,35,38,49$ \\
\hline Polyuria with acetazolamide & 33.3 & 5.6 & $26 / 78$ & $4 / 72$ & 4.24 (1.92 to 9.37$)$ & 3.6 (2.5 to 6.2$)$ & $31,37,40,47,49$ \\
\hline Paraesthesia with acetazolamide & 42.9 & 10.0 & $21 / 49$ & $5 / 50$ & 4.02 (1.71 to 9.43$)$ & $3.0(2.0$ to 6.0$)$ & $25,34,47,49$ \\
\hline
\end{tabular}

Cl=confidence interval. 

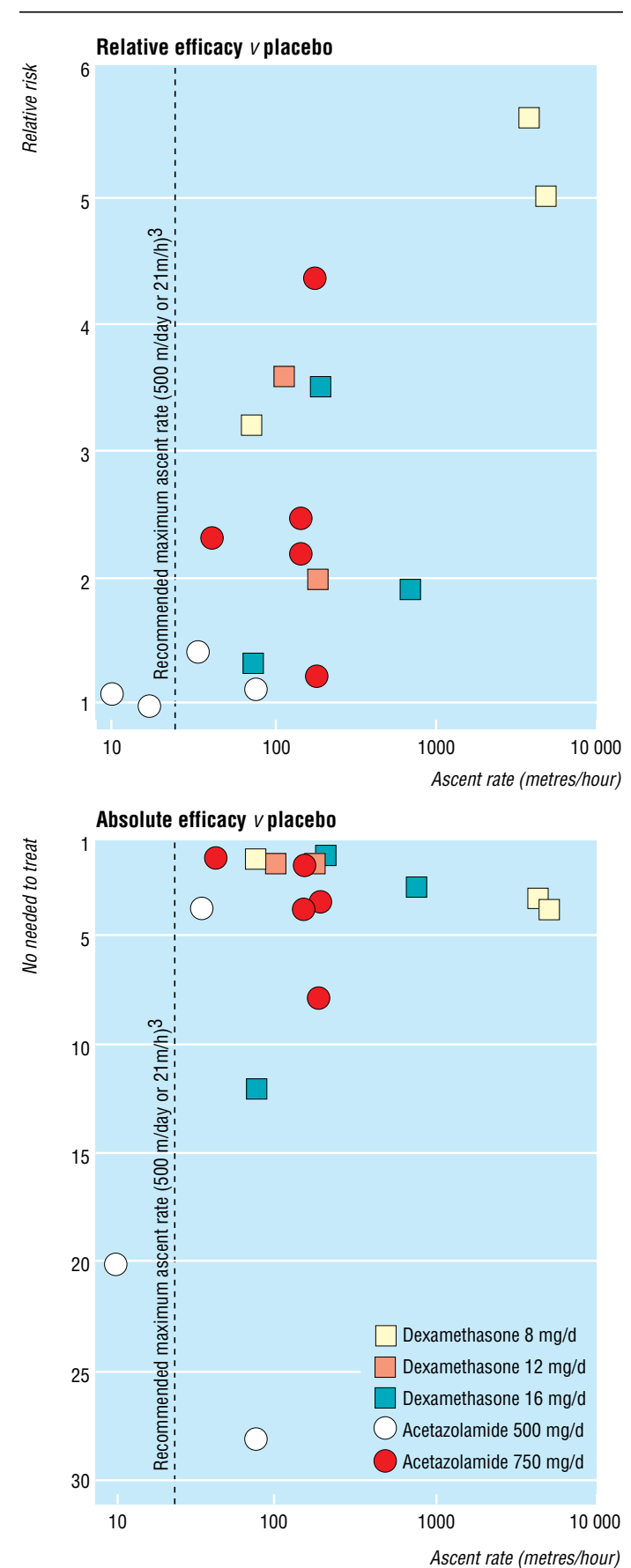

Fig 3 Relation between ascent rate and efficacy of pharmacological prevention of acute mountain sickness (17 trials; in the bottom graph one trial ${ }^{42}$ is omitted as event rates with placebo and with intervention were similar and thus the number needed to treat could not be calculated). Each symbol represents one trial; symbol sizes do not take into account trial size

prevention of high altitude oedema in 21 subjects (relative risk 2.5; NNT 1.9). ${ }^{18}$ In another trial, nifedipine was no different from placebo for preventing acute mountain sickness in 27 subjects. ${ }^{36}$ Spironolactone was more efficacious than placebo for preventing nausea in one trial with 19 subjects $(1.7 ; 2.5) .{ }^{37}$ Spironolactone was no different from placebo in preventing acute mountain sickness in 12 subjects, ${ }^{26}$ or in preventing headache or insomnia in 19 subjects. ${ }^{37}$
Among the interventions that were tested in one trial only, ginkgo biloba ${ }^{46}$ and aspirin ${ }^{28}$ showed significant improvement compared with placebo for at least one end point in 44 and 29 subjects respectively. Dihydroxyaluminium-sodium (45 subjects), ${ }^{43}$ codeine (15) ${ }^{30}$ phenformin (15), ${ }^{30}$ frusemide (furosemide) (23), ${ }^{22}$ phenytoin (21), ${ }^{48}$ and antidiuretic hormone $(22)^{22}$ did not show any efficacy compared with placebo for any of the reported end points.

\section{Adverse drug reactions}

Dichotomous data on adverse drug reactions were reported in 14 trials. $^{152223-3134353738-444749}$ In five trials (91 subjects) authors searched specifically for adverse effects resulting from weaning from dexamethasone (table 2). In three trials, no adverse effect was noticed; in one, 8 of 17 subjects taking dexamethasone $16 \mathrm{mg}$ / day $(0 / 8$ subjects taking placebo) experienced depression after the trip, ${ }^{49}$ and in another, 1 of 7 subjects taking dexamethasone $8 \mathrm{mg} /$ day ( $0 / 8$ taking placebo) experienced depression after stopping the treatment. ${ }^{35}$ When data were combined, the relative risk for adverse effects resulting from weaning from dexamethasone (including depression) was increased (NNT about 4). Gastrointestinal symptoms with dexamethasone were reported in two trials ${ }^{35}{ }^{39}$; the results were contradictory. With acetazolamide, polyuria (NNT about 4) and paraesthesia (NNT about 4) occurred significantly more often than with placebo (table 2). One trial reported taste disturbance in 3 of 15 subjects treated with acetazolamide, and in none taking placebo (not significant). ${ }^{49}$

\section{Discussion}

Above $4000 \mathrm{~m}$, dexamethasone $8-16 \mathrm{mg}$ and acetazolamide $750 \mathrm{mg}$ are equally efficacious in preventing acute mountain sickness when ascent rates are higher than $500 \mathrm{~m} /$ day. Fewer than three subjects need to be treated with one of these regimens for one subject not to experience acute mountain sickness who would have done so had they all received a placebo. Lower doses of dexamethasone $(0.5 \mathrm{mg}$ or $2 \mathrm{mg})$ and of acetazolamide $(500 \mathrm{mg}$ ) were not effective; they should not be used.

\section{Adverse effects}

In two trials in which dexamethasone was stopped abruptly, depression was reported. If this is confirmed in further trials, depression after withdrawal of dexamethasone might be considered a true risk. In the meantime, $8 \mathrm{mg}$ (that is, the minimal effective dose tested in these trials) should be used. We may assume that decreasing this dose stepwise after exposure to high altitude further decreases the risk of adverse effects from weaning. With acetazolamide, some adverse effects happened significantly more often than with placebo. These were, however, of minor severity only. People climbing or working at high altitude are unlikely to stop using acetazolamide because of paraesthesia in the fingertips or increased diuresis. There was a lack of data on efficacy and adverse effects for all the other drugs.

\section{Efficacy of prophylaxis}

To estimate efficacy of prophylaxis we need to know the underlying risk of the disease. The underlying risk is 
often poorly understood; then, the only way to establish guidelines on prophylaxis in "low risk" or "high risk" subjects is to assume that the control event rate in a randomised trial to some extent reflects the true underlying risk. Here, ascent rate could be identified as a key factor. At altitudes of $4000-6000 \mathrm{~m}$, the ascent rate clearly had an impact on the control event rate (fig 1). Thus, efficacy of pharmacological prevention of acute mountain sickness should be estimated in relation to the ascent rate. Experimental conditions represented different underlying risks. For each mode of ascent the direct relation between ascent rate and control event rate could be identified (fig 1). There was, however, a lack of evidence that the mode of ascent in itself had any impact on the efficacy of prophylaxis as none of the drugs was tested in all experimental conditions.

The relative benefit (that is, the relative risk) of prophylaxis with dexamethasone or acetazolamide compared with placebo depended directly on the ascent rate (fig 3). It ranged from "no relative benefit" (relative risk about 1) in trials with ascent rates below about $500 \mathrm{~m} /$ day $^{142}$ to a fivefold to sixfold relative improvement compared with placebo in trials with very high ascent rates. ${ }^{35} 45$ These data suggest that prophylaxis is worth while when ascent rates are high. The number needed to treat did not show the same degree of dependency from the ascent rate (fig 3). With low rates there was no absolute benefit with prophylaxis. ${ }^{12}$ Thus it may not be worth while to try to prevent acute mountain sickness at low ascent rates; too many subjects would have to be treated prophylactically for one to profit. With increasing ascent rates, absolute benefit of prophylaxis improved (that is, the number needed to treat decreased) and remained almost constant for effective regimens when ascent rates were $>500 \mathrm{~m} /$ day. Thus, both in relative and absolute terms, prophylaxis seems to be worth while when the ascent rate is high.

To interpret both the relative and the absolute benefit of prophylaxis it is equally important to test dose responsiveness. In relative terms, acetazolamide $750 \mathrm{mg}$ was more efficacious than $500 \mathrm{mg}$ (table 2, fig 3). However, as the higher dose was tested mainly in trials with faster ascent rates, any conclusion on dose responsiveness may be flawed. The difference in the absolute benefit (that is, the number needed to treat) of the two doses confirmed dose responsiveness. Within a range of ascent rates of $34 \mathrm{~m} /$ hour $^{1}$ to $179 \mathrm{~m} /$ hour, $^{19}$ $750 \mathrm{mg}$ was consistently more efficacious than $500 \mathrm{mg}$ (fig 3). Thus, recommendations on the optimal dose should be adapted. ${ }^{4}$

\section{Quality of included trials}

Most of the included trials were performed in field conditions; they were generally of acceptable quality according to the validated Oxford scale. Only about half of them, however, tried to blind both subjects and observers. Specific adverse reactions occurred frequently with the drugs and only rarely with placebo. Most of these trials may have suffered some degree of observer bias. Also, some trials were very small. No evidence existed, however, that smaller trials overestimated treatment effect compared with larger trials (fig 2). Finally, to extract homogeneous data and to minimise the risk of bias resulting from different definitions of end points, we concentrated on complete
What is already known on this topic

Acute mountain sickness is a disease frequently experienced at high altitude

Many drugs have been used to prevent acute mountain sickness

\section{What this study adds}

The risk of acute mountain sickness depends directly on the ascent rate; above $4000 \mathrm{~m}$, dexamethasone 8-16 $\mathrm{mg}$ and acetazolamide $750 \mathrm{mg}$ are equally efficacious in preventing acute mountain sickness when ascent rates are higher than $500 \mathrm{~m} /$ day

Contrary to widespread belief, acetazolamide $500 \mathrm{mg}$ does not work

Dexamethasone and acetazolamide are associated with specific adverse effects

With low rates of ascent, prophylaxis is not worth while

absence of acute mountain sickness. This dichotomous hurdle may be unnecessarily high. An intervention that does not completely prevent acute mountain sickness may alleviate symptoms to a great extent. Such an intervention may, of course, be useful.

\section{Research agenda}

As both dexamethasone and acetazolamide are efficacious in preventing acute mountain sickness but also carry a risk of adverse effects, should a combination of reduced doses of both drugs be tested? This was done in two trials only, ${ }^{24}{ }^{49}$ and the results were not conclusive. Nifedipine prevented high altitude pulmonary oedema. ${ }^{18}$ This is relevant because the incidence of clinical signs of high altitude pulmonary oedema may be $40 \%$ at above $3000 \mathrm{~m} \cdot{ }^{50-52}$ Together with data showing that nifedipine lowers pulmonary artery pressure ${ }^{36}$ these results may justify further research with this drug in high altitude conditions.

We thank Drs O Oelz, P Bärtsch, M Maggiorini, A Peacock, and $M$ Burtscher, who responded to our enquiry. We thank Daniel Haake from the documentation service of the Swiss Academy of Medical Science for his help in searching electronic databases.

Contributors: LD initiated the project. MRT coordinated the design of the project. LD and MRT searched for, extracted, and analysed the data. CM searched for and cross checked the extracted data. All authors participated in discussing the results and in writing the paper.

Funding: MRT received a Prosper grant (No 3233-05193997) from the Swiss National Science Foundation.

Competing interests: None declared.

1 Hackett PH, Rennie D, Levine HD. The incidence, importance, and prophylaxis of acute mountain sickness. Lancet 1976;2:1149-55.

2 Maggiorini M, Bühler B, Walter M, Oelz O. Prevalence of acute mountain sickness in the Swiss Alps. BMJ 1990;301:853-5.

3 Murdoch DR. How fast is too fast? Attempts to define a recommended ascent rate to prevent acute mountain sickness. Newsletter Int Soc Mountain Med 1999;3:3-6.

4 Food and Drug Administration. Acetazolamide for acute mountain sickness. FDA Drug Bulletin 1983;13:27.

5 Clarke C. Diamox, dexamethasone and nifedipine at high altitude. International Union of the Alpine Association (UIAA) Mountain Medicine Centre Information, Sheet 3. www.thebmc.co.uk/mm/mm3.html 1999 (accessed March 2000). 
6 Oelz O, Maggiorini M, Bärtsch P. Prevention and treatment of AMS and HAPE. In: Abstract book of the international congress of mountain medicine "Francois-Xavier Bagnoud." Interlaken, Switzerland: AKM Congress Service Basel, 1997;23.

7 Wilson I. Failure of acetazolamide to prevent acute mountain sickness. Postgrad Med J 1985;61:472.

8 Ramsay LE. Prophylaxis of acute mountain sickness. Lancet 1977;i:540-1.

9 Ried LD, Carter KA, Ellsworth A. Acetazolamide or dexamethasone for prevention of acute mountain sickness: a meta-analysis. $J$ Wilderness Med 1994;5:34-48

10 Jadad AR, Moore RA, Carroll D, Jenkinson C, Reynolds DJM, Gavaghan DJ, et al. Assessing the quality of reports of randomized clinical trials: is blinding necessary? Control Clin Trials 1996;17:1-12.

11 Morris JA, Gardner MJ. Calculating confidence intervals for relative risk, odds ratios, and standardised ratios and rates.. In: Gardner MJ, Altman DG, eds. Statistics with confidence. London: BMJ Publishing, 1995.

12 Yusuf S, Peto R, Lewis J, Collins R, Sleight P. Beta blockade during and after myocardial infarction: an overview of the randomized trials. Progr Cardiovasc Res 1985;27:335-71.

13 McQuay HJ, Moore RA. Using numerical results from systematic reviews in clinical practice. Ann Intern Med 1997;126:712-20.

14 Cook RJ, Sackett DL. The number needed to treat: a clinically useful measure of treatment effect. BMJ 1995;310:452-4.

15 Bradwell AR, Dykes PW, Coote JH, Forster PJ, Milles JJ. Effect of acetazolamide on exercise performance and muscle mass at high altitude. Lancet 1986;i:1001-5.

16 Bradwell AR, Coote JH. The BMRES 1984 Medical Research Expedition to the Himalayas. Postrad Med J 1987;63:165-7.

17 Morrissey SC, Keohane K, Coote JH. The effect of acetazolamide on breath holding at high altitude. Postgrad Med J 1987;63:189-90.

18 Bartsch P, Maggiorini M, Ritter M, Noti C, Vock P, Oelz O. Prevention of high-altitude pulmonary edema by nifedipine. $N$ Engl $J$ Med 1991;325:1284-9.

19 Kronenberg RS, Cain SM. Effect of acetazolamide on physiologic and subjective responses of men to 14000 feet. School of Aviation Medicine Technical Report 1967;67:1-10.

20 Goerre S, Wenk M, Bartsch P, Luscher TF, Niroomand F, Hohenhaus E, et al. Endothelin-1 in pulmonary hypertension associated with high-altitude exposure. Circulation 1995;91:359-64

21 Kronenberg RS, Cain SM. Effect of acetazolamide and hypoxia on cerebrospinal fluid bicarbonate. J Appl Physiol 1968;24:17-20.

22 Aoki VS, Robinson SM. Body hydration and the incidence and severity of acute mountain sickness. J Appl Physiol 1971;31:363-7.

23 Bernhard WN, Miller Schalick L, Gittelsohn A. Dexamethasone for prophylaxis against acute mountain sickness during rapid ascent to 5334 m. J Wilderness Med 1994;5:331-8.

24 Bernhard WN, Miller L, Delaney PA, Bernhard TM, Barnas GM. Acetazolamide plus low dose dexamethasone is better than acetazolamide alone to ameliorate symptoms of acute mountain sickness. Aviat Space Environ Med 1998;69:883-6.

25 Bradwell AR, Burnett D, Davies F. Acetazolamide in control of acute mountain sickness. Lancet 1981;i:180-3.

26 Brookfield DSK, Liston WA, Brown GV. Use of spironolactone in the prevention of acute mountain sickness on Kilimanjaro. East Afr Med J 1977;54:690-1.

27 Burki NK, Khan SA, Hameed MA. The effects of acetazolamide on the ventilatory response to high altitude hypoxia. Chest 1992;101:736-41.

28 Burtscher M, Likar R, Nachbauer W, Philadelphy M. Aspirin for prophylaxis against headache at high altitudes: randomised, double blind, placebo controlled trial. $B M J$ 1998;316:1057-8.

29 Cain SM, Dunn JE. Low dose of acetazolamide to aid accomodation of men to altitude. J Appl Physiol 1966;21:1195-200.

30 Carson RP, Evans WO, Shields JL, Hannon JP. Symptomatology, pathophysiology, and treatment of acute mountain sickness. Federation Proc 1969:28:1085-91.
31 Ellsworth AJ, Larson EB, Strickland D. A randomized trial of dexamethasone and acetazolamide for acute mountain sickness prophylaxis. Am J Med 1987;83:1024-30.

32 Ellsworth AJ, Meyer EF, Larson EB. Acetazolamide or dexamethasone use versus placebo to prevent acute mountain sickness on Mount Rainier. West J Med 1991;154:289-93.

33 Forwand SA, Landowne M, Follansbee JB, Hansen JE. Effect of acetazolamide on acute mountain sickness. N Engl J Med 1968;279:839-45.

34 Greene MK, Kerr AM, McIntosh IB, Prescott RJ. Acetazolamide in prevention of acute mountain sickness: a double-blind controlled cross-over study. BMJ 1981;283:811-3.

35 Hackett PH, Roach RC, Wood RA, Foutch RG, Meehan RT, Rennie D, et al. Dexamethasone for prevention and treatment of acute mountain sickness. Aviat Space Environ Med 1988;59:950-4.

36 Hohenhaus E, Niroomand F, Goerre S, Vock P, Oelz O, Bartsch P. Nifedipine does not prevent acute mountain sickness. Am J Respir Crit Care Med 1994;150:857-60.

37 Jain SC, Singh MV, Sharma VM, Rawal SB, Tyagi AK. Amelioration of acute mountain sickness: comparative study of acetazolamide and spironolactone. Int J Biometeorol 1986;30:293-300.

38 Jobe JB, Shukitt-Hale B, Banderet LE, Rock PB. Effects of dexamethasone and high terrestrial altitude on cognitive performance and affect. Aviat Space Environ Med 1991;62:727-32.

39 Johnson TS, Rock PB, Fulco CS, Trad LA, Spark RF, Maher JT. Prevention of acute mountain sickness by dexamethasone. $N$ Engl $J$ Med 1984;310:683-6.

40 Larson EB, Roach RC, Schoene RB, Hornbein TF. Acute mountain sickness and acetazolamide. Clinical efficacy and effect on ventilation. JAMA 1982;248:328-32.

41 Montgomery AB, Luce JM, Michael P, Mills J. Effects of dexamethasone on the incidence of acute mountain sickness at two intermediate altitudes. JAMA 1989:261:734-6.

42 Nicholson AN, Smith PA, Stone BM, Bradwell AR, Coote JH. Altitude insomnia: studies during an expedition to the himalayas. Sleep 1988;11:354-61.

43 Roach RC, Larson EB, Hornbein TF, Houston CS, Bartlett S, Hardesty J, et al. Acute mountain sickness, antacids, and ventilation during rapid, active ascent of Mount Rainier. Aviat Space Environ Med 1983;54:397-401.

44 Rock PB, Johnson TS, Cymerman A, Burse RL, Falk LJ, Fulco CS. Effect of dexamethasone on symptoms of acute mountain sickness at Pikes Peak, Colorado (4300m). Aviat Space Environ Med 1987;58:668-72.

45 Rock PB, Johnson TS, Larson RF, Fulco CS, Trad L, Cymerman A. Dexamethasone as prophylaxis for acute mountain sickness: Effect of dose level. Chest 1989;95:568-73.

46 Roncin JP, Schwartz F, D Arbigny P. EGb 761 in control of acute mountain sickness and vascular reactivity to cold exposure. Aviat Space Environ Med 1996:67:445-52.

47 Utz G, Schlierf G, Barth P, Linhart P, Wollenweber J. Prevention of acute mountain sickness using acetazolamide. Münch Med Wochenschr $1970 ; 112: 1122-4$.

48 Whons RNW, Colpitts M, Clement T, Karusa A, Blackett WB, Foutch R, et al. Phenytoin and acute mountain sickness on Mount Everest. Am J Med 1986;80:32-6.

49 Zell SC, Goodman PH. Acetazolamide and dexamethasone in the prevention of acute mountain sickness. West J Med 1988;148:541-5.

50 Hackett PH, Rennie D. Rales, peripheral edema, retinal hemorrhage and acute mountain sickness. Am J Med 1979;67:214-8.

51 Houston CS. High altitude illness-disease with protean manifestation. JAMA 1976;236:2193-5.

52 Coates G, Gray GW, Mansell A, Nahmias C, Powles A, Sutton J, et al. Changes in lung volume, lung density, and distribution of ventilation during hypobaric decompression. J Appl Physiol 1979;46:752-5.

(Accepted 14 April 2000)

\section{To coin a phrase}

A few cool days in London in the summer of 1929 are supposed to have given Alexander Fleming the chance to notice penicillin; the former Department of Health and Social Security named its headquarters after him. It stands beside the roundabout named Elephant \& Castle after the pub which was itself named after the arms of the Cutlers' Company for which it symbolised the ivory trade that gave the knives their handles.

Escaping one day from a tedious meeting in what we called the "Elephant House," at which doctors had disagreed on all kinds of principles, I was travelling in a bus round the corner in Walworth Road when I saw it. Over the door of a handsome brick building dated 1937, beneath a clustered family group whose adult held a caduceus, the lintel bore this inscription:

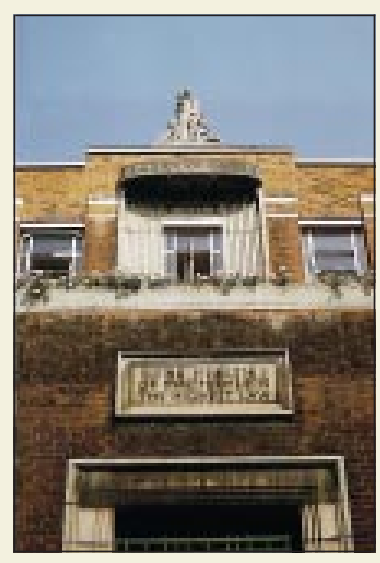

"THE HEALTH OF THE PEOPLE

IS THE HIGHEST LAW'

Where did the heady idealism of that slogan arrive from, cast in pride on Southwark's new health centre by its Metropolitan Borough all those years ago? None other than Cicero, and the Twelve Tables (451-450 BC)-the earliest written statement of the Roman law-"Salus Populi Suprema Lex."

That phrase today seems like a lighthouse among the debris of principles and priorities that have littered committee rooms during years of NHS politics. Good old LCC! And will Fleming's name be around in $4000+$ $\mathrm{AD}$ ?

Anthony Alment retired obstetrician and gynaecologist, Northampton 